\title{
CT-Scan vs MRI in Diagnosing Laryngeal Carcinoma
}

\author{
Mohammed Nizamuddin ${ }^{\circledR 1}$, Mohammed Naseeruddin ${ }^{\circledR 2}$, Anand Abkari ${ }^{\circledR 3}$ \\ ${ }^{1}$ Assisstant Professor, Department of Radiology, Deccan College of Medical Sciences, Hyderabad, Telangana, India, ${ }^{2}$ DMRD, Department of Radiology, Deccan College \\ of Medical Sciences, Hyderabad, Telangana, India, ${ }^{3}$ Emeritus Professor of Radio-Diagnosis, Deccan College of Medical Sciences, Hyderabad, Telangana, India.
}

\section{Abstract}

Background: MRI imaging offers more sensitivity than CT to cartilage invasion but results in a high rate of false-positive studies which decreases their overall accuracy. The objective is to compare accuracy of CT scan vs MRI in the laryngeal carcinoma. Subjects and Methods: All patients have been diagnosed, with and without contrast, including neck MRI and CT. In order to prevent invalidation, before laryngeal biopsy, MRI and CT scanning have been done such that the images are not altered by peri tumorous inflammation. Results: The MRI classification was right for 20 out of 25 patients ( 80 percent) and 5 outsized cases: three cT1b lesions were pT1a and two cT1a lesions were squamous cell papilloma's during pathological examination. CT was accurately identified in 17 out of 25 patients (68\%), with 8 understated cases: 3 cT1a lesions by CT were pT1b, 3 cT1a lesions were pT3, and 2 tumours had not been found in the CT scan. Conclusion: Our research showed that MRI in preoperative stage early glottic cancer is more sensitive than CT to accurately select eligible patients for conservatory larynx surgery like super cricoid laryngectomy and cordectomy.

Keywords: CT- Scan, MRI, Laryngeal Carcinoma, Glottic, Supraglottic, Subglottic.

Corresponding Author: Mohammed Nizamuddin, Assisstant Professor, Department of Radiology, Deccan College of Medical Sciences, Hyderabad, Telangana, India.

E-mail: drmdnizamuddin32@gmail.com

Received: 12 November 2020

Revised: 30 December 2020

Accepted: 13 January 2020

Published: 24 June 2020

\section{Introduction}

The most prevalent upper-aerodigestive cancer is laryngeal cancer. Laryngeal cancer accounts for $4.5 \%$ of all malignancies, while the upper aerodigestive tract cancer accounts for $28 \%$. Ninety percent of malignant larynx tumours consist of squamae cell carcinomas, with specific incidence ranges depending on the particular location of the infected subsite (glottic, supraglottic and subglottic). ${ }^{[1]}$ The clinical stage of diagnostic imaging is the most important stage in surgical preparation and will guarantee oncological radicality for patients with respect to clinical results.

The primary approaches to analyse laryngeal pathology are $\mathrm{CT}$ and MRI. The link between computerized tomography (CT scan) and magnetic resonance imaging (MRI) and histopathological results is important. The combined use of $\mathrm{CT}$ and MRI was shown in order to specifically classify the components of laryngeal tissue and to specifically delineate the degree of cancer dissemination.

The combined use of CT and MRI was shown in order to specifically classify the components of laryngeal tissue and to specifically delineate the degree of cancer dissemination.
In general MRI tends to be the best testing tool in cooperative patients, particularly for larynx assessment in preliminary laryngectomy attempts. The accuracy levels of CT and MRI in T laryngeal carcinoma could exceed $80 \%$ and $87 \%$, respectively, ${ }^{[2]}$ together with surgical reporting and laryngoscopy. Nevertheless, MRI had fairly high precision but poor specificity compared with $\mathrm{CT},{ }^{[3]}$ which either over-estimated or undervalued cartilage activity, in the measurement of anterior commissure lesions. ${ }^{[4-7]}$

The preference between the two modalities is decided often by one's understanding of them. The CT and MRI possibilities for the identification of cartilage invasions differ distinctly from one another. For identifying neoplastic cartilage interference, MRI appears to be more susceptible than CT, but has a much lower precision, for particular for the presence of thyroid cartilage. Imaging of tumour volume is increasing and signs of cartilage involvement can be significant for the risk of a tumour recurrence.

\section{Subjects and Methods}

\section{Place of Study}


Department of Radiology

\section{Type of study}

It's a standardised retrospective study.

\section{Sample Size}

25 symptomatic patients

\section{Inclusion Criteria}

All symptomatic patients pre clinically diagnosed were included in our study.

\section{Exclusion Criteria}

All patients with other forms of swelling including thyroid were excluded from our study.

All patients have been diagnosed, with and without contrast, including neck MRI and CT. In order to prevent invalidation, before laryngeal biopsy, MRI and CT scanning have been done such that the images are not altered by peri tumorous inflammation.

MRI and CT images were analysed to describe the distribution of the glottic lesion, the presence of anterior commissures, laryngeal cartilage penetration, and the possible expansion to sub glottic and/or supraglottic, and the invasion of Para glottic space. Both of the two sensitivity estimation methods as well as the accuracy and positive predictive value were contrasted with the outcome of MRI and CT and the final pathological test.

\section{Results}

The MRI classification was right for 20 out of 25 patients ( 80 percent) and 5 outsized cases: three cT1b lesions were pT1a and two cT1a lesions were squamous cell papilloma's during pathological examination. CT was accurately identified in 17 out of 25 patients (68\%), with 8 understated cases: 3 cT1a lesions by CT were pT1b, 3 cT1a lesions were pT3, and 2 tumours had not been found in the CT scan. A significant volume of false negatives is observed in CT scans, while MRI has reported three false positive events. CT does not overestimate cases, as opposed to MRI, but statistical significance is not attained. In patients with papilloma's, CT scans revealed no lesions although MRI indicated the glottis' asymmetry with incremental progress in lesion and presumption of malignancy.

In the estimation of the presence of the anterior commissure, there are statistically significant discrepancies between MRI and $\mathrm{CT}$ and there are often substantial variations for the Para glottic spatial analysis except though they are not statistically significant. The pathological correlation with MRI was $100 \%$ in all the laryngeal sites, while there were severe discrepancies in correlation with CT-Scan.

In addition, a proportion of sub stadial rates equivalent to 0 percent for MRI and 33 percent for CT exist taking into account the clinical-radiological $\mathrm{T}$ phases of $\mathrm{pT}$ phases that attain statistics.

\section{Discussion}

This research assesses the role of MRI and CT in the clinical stage of early glottic cancer (T1-T2) to the evaluation of submucosal areas that may change the disease's stage and reassess the therapeutic strategy. In the field of assessment fields such as para glottis, anterior commissure, thyroid and arytenoid cartilages, MRI especially has sensitivity of 100 percent and specificities of 97 percent and separate indications for conservative operation. Alternatively, the sensitivity of CT is $40 \%$ smaller, but it is extremely precise $(100 \%)$. In our series, $70 \%$ of CT scans were accurate, while in $80 \%$ of cases, the MRI was accurate. By KUNO et al, the CT precision in stage setting was 80 percent and 87.5 percent, whereas for the determination of cartilaginous invasion MRI displayed a more robust sensitivity than $\mathrm{CT}$ scan, without substantial variations between MRI and CT - scan in the assessment of anterior commissure and Para glottic space. However, cartilage penetration is often overestimated and some patients undergo complete laryngectomy. ${ }^{[7]}$ Once again, the integration of DWI into the MRI could improve the specificity of the procedure. ${ }^{[8]}$

Several authors have examined the ability of CT to evaluate cartilage invasions, resulting in a variable sensitivity between 46 and $74 \%$ and a variable specificity between 87 and 94 percent. ${ }^{[9-11]}$

In our study, CT has underscored the invasion of thyroid cartilage and paraglottic space; in a patient with bilateral glottic cancer, CT has not assessed the invasion of anterior commissure and, in another situation, no tumour alteration has been reported.

\section{Conclusion}

In our research, statistical analyses suggest that MRI can be considered a beneficial way of diagnosing the laryngeal tumour preoperatively and making decisions in such patients as the best therapeutic alternative. Although MRI is costlier, longer and not always feasible compared to CT scanning for patients.

\section{References}

1. Ortholan C, Benezery K, Dassonville O, Poissonnet G, Bozec A, Guiochet N, et al. A specific approach for elderly patients with head and neck cancer. Anticancer Drugs. 2011;22(7):647-655. Available from: https://dx.doi.org/10. 1097/cad.0b013e328344282a. 


\begin{tabular}{|c|c|c|c|c|c|c|c|c|}
\hline \multirow[t]{2}{*}{ Site } & \multirow{2}{*}{$\begin{array}{l}\text { MRI } \\
\text { True } \\
\text { ber }\end{array}$} & CT - SCAN & MRI & $\begin{array}{l}\text { CT - } \\
\text { SCAN }\end{array}$ & MRI & $\begin{array}{l}\text { CT } \\
\text { SCAN }\end{array}$ & MRI & $\begin{array}{ll}\text { CT } & - \\
\text { SCAN } & \end{array}$ \\
\hline & & Positive Num- & \multicolumn{2}{|c|}{ False Positive Number } & \multicolumn{2}{|c|}{$\begin{array}{l}\text { True Negative Num- } \\
\text { ber }\end{array}$} & \multicolumn{2}{|c|}{$\begin{array}{l}\text { False Negative Num- } \\
\text { ber }\end{array}$} \\
\hline Para glottic space & 7 & 3 & 0 & 0 & 15 & 15 & 0 & 5 \\
\hline Thyroid cartilage & 5 & 3 & 0 & 0 & 17 & 17 & 0 & 3 \\
\hline Arytenoid cartilage & 3 & 3 & 0 & 0 & 19 & 19 & 0 & 0 \\
\hline Cricoid cartilage & 0 & 0 & 0 & 0 & 21 & 21 & 0 & 0 \\
\hline Anterior commissure & 10 & 3 & 3 & 0 & 11 & 13 & 0 & 9 \\
\hline
\end{tabular}

Table 2: Confirmation of pathological, MRI and CT staging of importance dependent on laryngeal subsites.

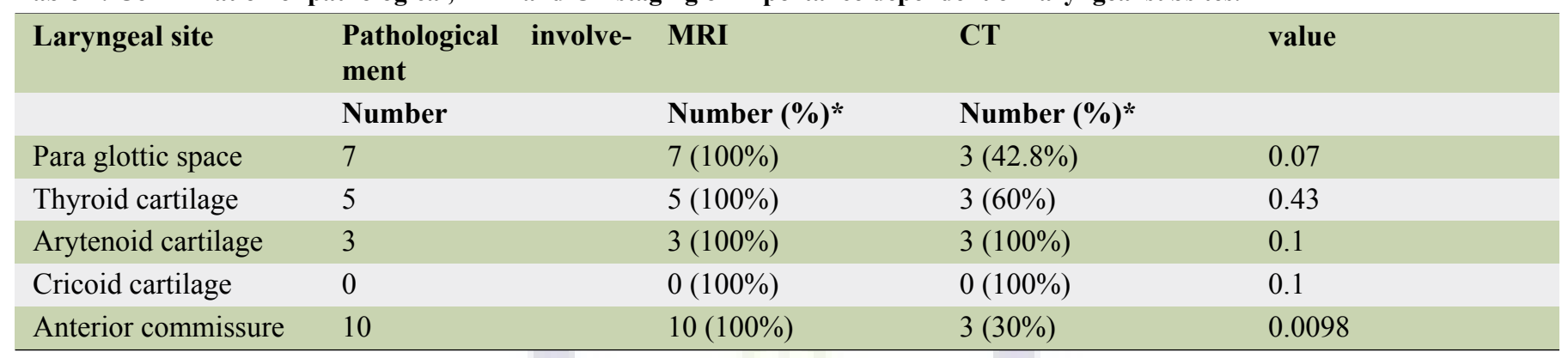

Table 3: Percentage of concordance between pathological, MRIvs CT T staging with P value

\begin{tabular}{llll}
\hline T staging & MRI & CT - Scan & P value \\
Correct stadiations & $90 \%$ & $76 \%$ & 0.3 \\
Understadiations & $9 \%$ & $0 \%$ & 0.5 \\
Overstadiations & $0 \%$ & $23 \%$ & 0.01 \\
\hline
\end{tabular}

2. Zbären P, Becker M, Läng H. Staging of laryngeal cancer: Endoscopy, computed tomography and magnetic resonance versus histopathology. Eur Arch Otorhinolaryngol. 1997;254(S1):S117-S122. Available from: https://dx.doi.org/ 10.1007/bf02439740.

3. Becker M, Zbären P, Laeng H, Stoupis C, Porcellini B, Vock $\mathrm{P}$. Neoplastic invasion of the laryngeal cartilage: comparison of MR imaging and CT with histopathologic correlation. Radiology. 1995;194(3):661-669. Available from: https://dx. doi.org/10.1148/radiology.194.3.7862960.

4. Becker M. Neoplastic invasion of laryngeal cartilage:radiologic diagnosis and therapeutic implications. Eur J Radiol. 2000;33:216-229. Available from: https://dx.doi.org/10.1016/ s0720-048x(99)00144-8.

5. Li B, Bobinski M, Gandour-Edwards R, Farwell DG, Chen AM. Overstaging of cartilage invasion by multidetector CT scan for laryngeal cancer and its potential effect on the use of organ preservation with chemoradiation. $\mathrm{Br} \mathrm{J}$ Radiol. 2011;84(997):64-69. Available from: https://dx.doi.org/10. 1259/bjr/66700901.

6. Hartl DM, Landry G, Hans S, Marandas P, Brasnu DF. Organ preservation surgery for laryngeal squamous cell carcinoma: Low incidence of thyroid cartilage invasion. Laryngoscope.
2010;120(6):1173-1176. Available from: https://dx.doi.org/10. 1002/lary.20912.

7. Kuno H, Onaya H, Fujii S, Ojiri H, Otani K, Satake M. Primary staging of laryngeal and hypopharyngeal cancer: CT, MR imaging and dual-energy CT. Eur J Radiol. 2014;83(1):2335. Available from: https://dx.doi.org/10.1016/j.ejrad.2013.10. 022.

8. Becker M, Zbären P, Casselman JW, Kohler R, Dulguerov P, Becker CD. Neoplastic Invasion of Laryngeal Cartilage: Reassessment of Criteria for Diagnosis at MR Imaging. Radiology. 2008;249(2):551-559. Available from: https://dx. doi.org/10.1148/radiol.2492072183.

9. Zbaren P, Becker M, Lang H. Pretherapeutic staging of laryngeal carcinoma clinical findings, computed tomography, and magnetic resonance imaging compared with histopathology. Cancer. 1996;77(7):1263-1273. Available from: https://dx.doi.org/10.1002/(sici)1097-0142(19960401)77: 7<1263::aid-cncr6>3.0.co;2-j.

10. Sulfaro S, Barzan L, Querin F, Lutman M, Caruso G, Comoretto $\mathrm{R}$, et al. T Staging of the Laryngohypopharyngeal Carcinoma: A 7-Year Multidisciplinary Experience. Arch Otolaryngol Head Neck Surg. 1989;115:613-620. Available from: https: 
//dx.doi.org/10.1001/archotol.1989.01860290071017.

11. Bertrand M, Tollard E, François A. CT scan, MR imaging and anatomopathologic correlation in the glottic carcinoma T1-T2. Revue des Maladies Respiratoire. 2010;131(1):51-57.

Copyright: (C) the author(s), 2020. It is an open-access article distributed under the terms of the Creative Commons Attribution License (CC BY 4.0), which permits authors to retain ownership of the copyright for their content, and allow anyone to download, reuse, reprint, modify, distribute and/or copy the content as long as the original authors and source are cited.

How to cite this article: Nizamuddin M, Naseeruddin M, Abkari A. CT-Scan vs MRI in Diagnosing Laryngeal Carcinoma. Asian J. Med. Radiol. Res. 2020;8(1):54-57.

DOI: dx.doi.org/10.47009/ajmrr.2020.8.1.11

Source of Support: Nil, Conflict of Interest: None declared. 